\title{
AVALIAÇÃo FÍSICO-QUÍMICA E PARASITOLÓGICADE ÁGUAS DE BEBEDOUROS DE UMA INSTITUIÇÃO DE ENSINO SUPERIOR DE SOBRAL-CE
}

Andréa Maria NEVES ${ }^{1}$

Lílian Alves MARINHO ${ }^{2}$

Chayanna da Silva FERREIRA ${ }^{3}$

Maria Gleiciane Soares COUTINHO ${ }^{4}$

Murilo Sérgio da Silva JULIÃO 5

Raquel Oliveira dos Santos FONTENELLE ${ }^{6}$

${ }^{1}$ Graduanda do curso de Ciências Biológicas da Universidade Estadual Vale do Acaraú - UVA, andreamarianeves@gmail.com

${ }^{2}$ Graduanda do curso de Química da Universidade Estadual Vale do Acaraú - UVA, lih.marinho@hotmail.com

${ }^{3}$ Graduada do curso de Ciências Biológicas pela Universidade Estadual Vale do Acaraú - UVA, chayanna_cfs@hotmail.com

${ }^{4}$ Graduada do curso de Ciências Biológicas pela Universidade Estadual Vale do Acaraú - UVA, gleycy-soares1@hotmail.com

${ }^{5}$ Professor do curso de Química da Universidade Estadual Vale do Acaraú - UVA, murilo-sergio@uol.com.br

${ }^{6}$ Professora do curso de Ciências Biológicas da Universidade Estadual Vale do Acaraú - UVA, raquelbios@yahoo.com.br

Recebido em: 08/11/2015 - Aprovado em: 18/07/2016 - Disponibilizado em: 18/12/2016

\begin{abstract}
RESUMO
Água potável se refere a toda água acessível na natureza que possui atributos que não oferecem perigosaos seres vivos que a consomem. Através dos serviços de tratamento e abastecimento de água,pode-se perceber que a água tratada oferece melhoria nas condições de vida e saúde de uma comunidade por meio do monitoramento e prevenção de doenças. O objetivo deste estudo foi verificar as condições físico-químicas e parasitológicas das águas de bebedouros de uma instituição de ensino superior de Sobral, Ceará. Para a realização dos ensaios foram coletadas dez amostras das águas dos bebedouros, sendo cinco destinadas para ensaios físico-químicos e cinco para ensaios parasitológicos. Foram determinados os seguintes parâmetros: físico-químicos (nitrato, nitrito, cloreto e $\mathrm{pH}$ ) e parasitológicos: observação de estruturas parasitárias pelo método de sedimentação espontânea. Os resultados obtidos para os parâmetros físicoquímicos mostraram-se em conformidade com as especificações estabelecidas pela Portaria No 2914 do Ministério da Saúde, que estabelece os valores aceitáveis para os parâmetros analisados. Entretanto, os resultados obtidos para os parâmetros parasitológicos estão em desacordo com a Portaria No 2914do Ministério da Saúde, que dispõe sobre os procedimentos de controle e de vigilância da qualidade da água para consumo humano e seu padrão de potabilidade.

Palavras chave:Água potável. Bebedouros. Análise físico-química. Análise parasitológica.
\end{abstract}

\begin{abstract}
Drinking water refers to all water available in nature that has attributes that do not dangers to living beings who consume it. Through treatment and water supply, it can be seen that the treated water provides improvement in living conditions and health of a community by monitoring and disease prevention. The aim of this study was to determine the physicochemical and parasitological conditions of the troughs of water from a higher education institution of the Sobral, Ceará. For the tests were collected ten samples of water from drinking fountains, five designed for physico-chemical tests and five for parasitological testing. It was determined the following parameters: physico-chemical (nitrate, nitrite, chloride and $\mathrm{pH}$ ) and parasitological: observation of parasitic structures by spontaneous sedimentation method. Results for the physico-chemical parameters were in accordance with the specifications established by the Ministry of Health


Ordinance No. 2914, establishing the acceptable values for the parameters analyzed. However, results obtained for the parasitological parameters are not in accordance with Ordinance of the Ministry of Health No. 2914, which establishes the procedures for control and surveillance of water quality for human consumption and its potability standards.

Keywords: Potable water. Drinking fountains.Physical and chemical analysis. Parasitological analysis

\section{INTRODUÇÃO}

A água potável é imprescindível para a manutenção dos seres vivos,a atividade dos ecossistemas e o desenvolvimento econômico. No entanto, o aumento populacional e a explosão de atividades agrícolas e industriais realizadas pelo homem nos últimos anos, acarretou um crescente consumo e degradação deste recurso, tornando-o mais escasso (MUNIZ, 2013).

A água utilizada para abastecimento público deve ser tratada para atender aos padrões de potabilidade,segundo algunsparâmetros físicos, químicos, radioativos e microbiológicos estabelecidos pela legislação vigente, de forma a não oferecer riscos á saúde do consumidor (CASTRO; SILVA; FABRI, 2013). A água é um recurso capaz de veicular contaminantes químicos e microbiológicos provocando danos à saúde humana, tal fato é caracterizado pela capacidade que essa substância possui de dissolver inúmeras substâncias consideradas insolúveis (CORREA; AMARAL, 2012). De acordo com a Organização Mundial de Saúde cerca de $80 \%$ das patologias que ocorrem em países em desenvolvimento são causadas por águas contaminadas (ZULPOet al., 2006).
As septicemias parasitárias intestinais tornaram-se um grande problema de saúde pública no Brasil, representando um sério obstáculo para a população, acometendo principalmente pessoascom nível socioeconômico mais baixo e que não apresentam sistema de saneamento básico de qualidade (ROQUE, 2005). As enteroparasitoses provocam decrescimento na qualidade de vida da população e como resultado, dificultam a aprendizagem, além de acometer alguns órgãos vitais, colaborando desta forma para o aumento da desnutrição resultando assim em altos índices de morbidade (MATOS,2012).

O tratamento necessário para que a água seja considerada potável, abrange um conjunto de etapas realizadas nas estações de tratamento de água (ETAs) pelas quais este recurso deve passar com o propósito depoder ser consumida pelos seres humanos. Além disso, é importante tambémque se faça uma limpeza contínua dos reservatórios de água, como bebedouros e torneiras, evitando desta forma que impurezas presentes na água, não venham prejudicar a água que adentra nas residências através da rede de distribuição, em condições de potabilidade (PEZENTE, 2009).

De acordo com a Portaria $n^{\circ} 2914$ de 2011 (BRASIL, 2011) emitidas pelo 
Ministério da Saúde, que estabelece os padrões de potabilidade, avalia que a água designada ao consumo humano deve atender as particularidades que estejam de acordo com os valores admissíveis quanto aos parâmetros físico-químicos, organolépticos e microbiológicos, assegurando à população que a água chegue de forma confiável, para que possa ser utilizada para consumo humano (GIRARDI, 2012).

A determinação qualitativa e quantitativa de parâmetros físico-químicos da água e de suas soluções tem como finalidade identificar e quantificar os elementos e compostos iônicos existentes nessassoluções e associaràs questões ecológicas, permitindo a compreensão dos processos naturais ou alterações no meio ambiente (PARRON; MUNIZ; PEREIRA, 2011).

Diante da importância dos cuidados com a água que consumimos, o presente estudo teve como objetivo verificar as qualidades físico-química e parasitológica de amostras de água consumida por estudantes nos bebedouros de uma universidade pública localizada emSobral-CE.

\section{MATERIAIS E MÉTODOS}

Para opresente estudo foram coletadas amostras de água de cinco bebedouros em uma universidade pública de Sobral-CE, nos períodos de abril e maio de 2014, sendo que foram realizadas umadeterminação físicoquímica e uma análise parasitológica para cada bebedouro, totalizando 10 análises. Os pontos de coleta foram classificados como A,B, C, D e E.

As amostras de água foram coletadas em frascos previamente estéreis, com capacidade para $1000 \mathrm{~mL}$. Após a coleta, os recipientes foram vedados, identificados e acondicionados em caixas isotérmicas e posteriormente conduzidos para serem analisados nos Laboratórios de Microbiologia e de Química Analítica Aplicada da Universidade Estadual Vale do Acaraú-UVA.

As análises físico-químicas foram realizadas seguindo as normas do Instituto Adolf Lutz (IAL, 2005) e os seguintes parâmetrosforam determinados: nitrato, nitrito, cloreto e $\mathrm{pH}$.

Para a determinação deíons nitrato $\left(\mathrm{NO}_{3}{ }^{-}\right)$, a amostra de água foi transferida para um balão volumétrico de $100 \mathrm{~mL}, 1,0 \mathrm{mLde}$ ácido clorídricofoi então adicionado e depois homogeneizada. A partir desta solução, uma curva de calibração foi construída com os valores de absorbância medidos a $205 \mathrm{~nm}$, num espectrofotômetro (Micronal), e a quantidade de nitrogênio nítrico foi determinada.

A determinação de íons nitrito $\left(\mathrm{NO}_{2}^{-}\right)$ foi realizada por volumetria de óxido-redução com solução padronizada de permanganato de potássio $0,10 \mathrm{molL}^{-1}$ até o aparecimento de uma coloração rósea. 
Para a determinação de íons cloreto $\left(\mathrm{Cl}^{-}\right)$foram utilizados $100 \mathrm{mLde}$ cada uma das amostras, nas quaisfoi adicionada uma pequena quantidade de $\mathrm{CaCO}_{3}$ e 4 gotas de $\mathrm{K}_{2} \mathrm{CrO}_{4} \mathrm{a} 5,0 \%(\mathrm{~m} / \mathrm{V})$. Posteriormente, esta mistura foi titulada com uma solução padronizada de nitrato de prata $0,01 \mathrm{~mol} \mathrm{~L}^{-}$ ${ }^{1}$ até atingir o ponto de equivalência.

As medidas depHforam realizadas em 50,0 mL de cada amostra de água num potenciômetro (Metrohm) calibrado e conectado a um eletrodo de $\mathrm{pH}$ (Metrohm).

Para avaliar a presença de estruturas parasitárias, as amostras foram submetidas à técnica de sedimentação espontânea, onde ficaram em repouso por 24 horas em cone de sedimentação Imhoff. Posteriormente, fez-se a coleta de $10,0 \mathrm{~mL}$ do sedimento em tubo Falcon onde também foram adicionados $3,0 \mathrm{~mL}$ de zinco a $33 \%$, as amostras foram centrifugadas por 3 minutos a $2.500 \mathrm{rpm}$. Depois foram analisadas em duplicata e coradas com lugol para pesquisa de ovos ou larvas de helmintos. As lâminas foram observadas ao microscópio óptico utilizando as objetivas de aumento de 10x e 40x (DE CARLI, 2001).

\section{RESULTADOS E DISCUSSÃO}

Os resultados das determinações de nitrato, nitrito, cloreto e pHapresentados na Tabela 1estão em acordo com os valores máximos aceitáveis pela Portaria ${ }^{\circ} 2.914$ do Ministério da Saúde (BRASIL, 2011).
Tabela 1 -Resultados dos parâmetros físicoquímicos obtidos para amostras de águas de bebedouros consumidas por estudantes de uma universidade pública em Sobral-CE.

\begin{tabular}{|c|c|c|}
\hline Parâmetro & $\begin{array}{c}\text { Média } \\
(\mathrm{mg} / \mathrm{mL})\end{array}$ & $\begin{array}{c}\text { VMP } \\
(\mathrm{mg} / \mathrm{mL})\end{array}$ \\
\hline Nitrato & 1,092 & $10 \mathrm{mg} / \mathrm{L}$ \\
\hline Nitrito & 0,033 & $1,0 \mathrm{mg} / \mathrm{L}$ \\
\hline Cloreto & 37,35 & $<250 \mathrm{mg} / \mathrm{L}$ \\
\hline $\mathrm{pH}$ & 7,27 & 6,0 a 9,5 \\
\hline
\end{tabular}
2015.

$\mathrm{O}$ íon nitrato $\left(\mathrm{NO}_{3}{ }^{-}\right)$ocorre frequentemente em águas superficiais em quantidade de traços, mas podem atingir níveis elevados em algumas águas subterrâneas. É encontrado em esgotos domésticos em pequenas quantidades, no entanto em efluentes de estações de tratamento biológico nitrificante, pode ser encontrado em concentrações acima do permitido. $\mathrm{O}$ nitrito $\left(\mathrm{NO}_{2}{ }^{-}\right)$ocorre tanto pela oxidação do íon amônio $\left(\mathrm{NH}_{4}{ }^{+}\right)$como pela redução do $\mathrm{NO}_{3}{ }^{-}$. Os processos de oxidação e redução ocorrem em sistemas de distribuição de água e em águas naturais, bem como em estações de tratamento de esgoto (PARRON; MUNIZ; PEREIRA, 2011).

Com relação à concentração de nitrato e nitrito nas amostras de água coletadas nos bebedouros foi verificada que todas apresentaram valores aceitáveis segundo a legislação vigente, Tabela 1. O mesmo foi observado por Damianiet al (2013) ao avaliar a qualidade física e química das águas 
provenientes de bebedouros consumidos por estudantes de Goiânia-GO.

Nas ETAs, a adição de cloro $\left(\mathrm{Cl}_{2}\right)$ à água, faz com que haja um aumento na concentração de íons cloreto, decorrente das reações de dissociação $\mathrm{doCl}_{2}$ na água. $\mathrm{O}$ cloreto não apresenta toxicidade ao ser humano, a não ser no caso da deficiência no metabolismo de cloreto de sódio, por exemplo, na insuficiência cardíaca congestiva. A concentração de íons cloreto em águas de consumo público representa um padrão de aceitamento, já que confere um sabor “salgado”à água (CASTRO; SILVA;FABRI, 2013).

Em relação aos teores de cloreto determinados nas amostras de água dos bebedouros, pode-se afirmar também que todas estão de acordo com os padrões de potabilidade estabelecidos pela Portaria $\mathrm{n}^{\circ} 2.914$ (BRASIL, 2011), a qual determina uma quantidade máxima de 250mg/L. Carvalho et al(2009) verificaram em seu trabalho que todas as amostras de água oriundas de bebedouros docampus de uma universidade de Ipatinga-MG estavam de acordo os padrões estabelecidos pela legislação vigente para íons cloretos.

O pHrepresenta a medida da quantidade de íons de hidrogênio $\left(\mathrm{H}^{+}\right)$ presente em soluções aquosas e pode ser utilizado para avaliar o grau de alcalinidade ou de acidez de uma amostra. O pH é um parâmetro que deve ser frequentemente analisado, pois este pode prejudicar o processo de coagulação-precipitação química durante o tratamento de água, no crescimento microbiano dos sistemas biológicos de tratamento, na toxicidade de certos compostos, nos constituintes da alcalinidade e acidez da água e na corrosão de tubulações e equipamentos. (MAGALHÃESet al., 2014).

A Tabela 1 mostra os resultados obtidos para $\mathrm{pH}$, e foi verificado que todas as amostras estão dentro dos limites permitido para consumo de acordo com a Portaria n².914 do Ministério da Saúde, apresentando um $\mathrm{pH}$ médio $=7$,27. Estes resultados são semelhantes aos encontrados por Pezente (2009), que ao avaliar a qualidade física e química da água dos bebedouros de uma escola de Timbé do Sul, verificou a conformidade desse parâmetro com os padrões estabelecidos pela legislação.

Os resultados obtidos das análises parasitológica das águasestão especificadas na Tabela 2.No presente estudo foram avaliadas cinco amostras de água oriundas de cinco bebedouros através do método de sedimentação espontânea. Dessas amostras, três: A, C e D apresentaram resultado positivo no exame parasitológico para diferentes ovos de helmintos e nas amostras $B$ e Eos resultados foram negativos.

De acordo com os resultados apresentados na Tabela 2 foi verificado que, os 
ovos de helmintos encontrados foram: Ancylostomasp.no bebedouro C (20\%); Entamoebasp.nos bebedouros C e D (40\%); Ascaris sp.no bebedouro A e D (40\%); Giardiasp.nos bebedouros A, C e D (60\%) e Trichurissp. no bebedouro D (20\%). Já os bebedouros $\mathrm{B}$ e E não apresentaram nem uma contaminação por parasitos.

Tabela 2 -Prevalência e etiologia dos parasitas presentes nos bebedouros

\begin{tabular}{|c|c|}
\hline Etiologia & $\begin{array}{c}\mathbf{N}^{\circ} \text { DE BEBEDOUROS } \\
\text { CONTAMINADOS (\%) }\end{array}$ \\
\hline Ancylostoma & $20 \%$ \\
\hline Entamoebasp. & $40 \%$ \\
\hline Ascaris sp. & $40 \%$ \\
\hline Giardiasp. & $60 \%$ \\
\hline Trichurissp. & $20 \%$ \\
\hline
\end{tabular}

FONTE: Próprio autor, 2015.

Os valores encontrados são semelhantes aos encontrados por Borges (2011) ao avaliar a prevalência de parasitos intestinais de Giardialamblia em pacientes atendidos pelo serviço público de saúde da região sudeste de Goiás em que, houve uma prevalência de33,6\% para Giardialamblia.

Os padrões de qualidade da água para os indicadores parasitológicos cuja presença ou ausência está vinculada aos indicadores microbiológicos, portanto, de acordo com a Portaria $\mathrm{N}^{\circ}$ 2.914, de dezembro de 2011 que, dispõe sobre os procedimentos de controle e de vigilância da qualidade da água para consumo humano a ausência de bactérias do grupo coliformes e termotolerantes. Assim sendo, as amostras analisadas não atenderam as normas estabelecidas pela legislação vigente.

O alto índice do protozoário Giardia encontrado nas águas provenientes dos bebedouros pode está associado a uma possível contaminação em virtude do estado de conservação que alguns bebedouros se encontravam, pois apresentavam torneiras quebradas e entupidas impedindo a passagem contínua de água, indicando ausência de manutenção.

Diante das patologias causadas por protozoários e helmintos, tornou-se necessário a adesão de ações preventivas, a fim de evitar os prejuízos causados à população pelas doenças infecciosas e parasitárias. As enfermidades ocasionadas por estes microorganismos geram grandes impactos sociais, afetando tipicamente países em desenvolvimento acometendo principalmente a classe socioeconômica mais baixa e que, segundo a OMS afetam mais de 1 bilhão de pessoas ao redor do mundo (SANTOS, 2012).

\section{CONCLUSÃO}

Os resultados obtidos possibilitam compreender que as amostras de águas coletadas nos bebedouros da instituição de ensino superior estudada podem ser consideradas próprias para consumo humano para os parâmetros físico-químicos, pesquisados neste estudo. Entretanto, os resultados obtidos para os parâmetros 
parasitológicos estão em desacordo com a legislação vigente.

Os resultados das avaliações físicoquímicas e parasitológicas foram de fundamental importância, pois desta forma pode-se advertir que em relação à qualidade da água acessível para consumo, tanto para alunos, professores, funcionários ou quaisquer pessoas que dela consumir, poderão estar em risco quanto às questões advindas pela falta de controle de tratamento adequado.

\section{REFERÊNCIAS}

BORGES, W.F.; MARCIANO, F.M.; OLIVEIRA, H.B. Parasitoses intestinais: Elevada prevalência de Giardialamblia em pacientes atendidos pelo serviço público de saúde da região sudeste de Goiás. Brasil. Revista de Patologia Tropical, Goiás, v.40, n. 2, p. 149-157, abr/jun. 2011.

BRASIL. Ministério da Saúde. Secretaria de Vigilância Sanitária. Portaria $\mathrm{n}^{\circ} .2914$ de Dezembro de 2011. Diário oficial da União, Brasília, 2011.

CARVALHO, D.R. et al. Avaliação da qualidade físico-química e microbiológica da água de um campus universitário de IpatingaMG.NUTRIR GERAIS- Revista Digitalde Nutrição, Ipatinga, v.3, n.5, p. 417-427, ago/dez. 2009.

CASTRO, A. Z.; SILVA, B.M.; FABRI, R.L. Avaliação da qualidade físico-química e microbiológica da água dos bebedouros de uma instituição de ensino superior de Juiz de Fora, Minas Gerais. NUTRIR GERAISRevista Digital de Nutrição. Juiz de Fora, v. 7, n. 12, p. 984-998, fev/jul. 2013.
Esta pesquisa propicia uma visível representação da qualidade da água consumida nos bebedouros da instituição de ensino superior de Sobral-CEno período analisado, e para obtenção de valores mais confiáveis, é indispensável que se faça um estudo mais profundo, com coletas mensais de várias amostras por um período maior de tempo.

CORREA, Deyse Aparecida.; AMARAL, Ligiane. Análise microbiológica da água e torneiras dos bebedouros das escolas do município de Campo Gerais e Ilicínea-MG. 2012. 53 f. Trabalho de conclusão de curso (Graduação em Ciências Biológicas)Faculdade de Ciências e Tecnologias de Campos Gerais, Campos Gerais, 2012.

DAMIANI, C. et al. Avaliação física e química de água de bebedouros consumida por estudantes da UFG, Gôiania, GO. Higiene Alimentar, Goiás, v.27, n. 216, p.189-193, jan/fev. 2013.

DE CARLI G. A. Parasitologia Clínica: seleção de métodos e técnicas de laboratório para o diagnóstico de parasitoses humanas. São Paulo: Editora Atheneu, 810 pp. 2001.

GIRARDI, A.P. Avaliação da qualidade bacteriológica da água de instituições de ensino do município de São Miguel do Oeste/SC. 2012.42f. Trabalho de Conclusão de Curso (Especialização em MBA Gestão Ambiental, Ênfase em Licenciamento, Perícia e Auditoria Ambiental)- Universidade do Oeste de Santa Catarina, São Miguel do Oeste/SC, 2012.

INSTITUTO ADOLFO LUTZ. Normas Analíticas do Instituto Adolfo Lutz: 148

Revista da Universidade Vale do Rio Verde, Três Corações, v. 14, n. 2, p. 142-149, ago./dez. 2016 
Métodos físico- químicos para análise de água. Brasília: IAL; 2005.

MAGALHÃES, Y.A. et al. Qualidade Microbiológica e Físico-Química da Água dos Açudes Urbanos Utilizados na Dessedentação Animal em Sobral, Ceará . Revista daUniversidade Vale do Rio Verde, Três Corações, v. 12, n. 2, p. 141-148, ago./dez. 2014.

MATOS, M.A.; CRUZ, Z.V. Prevalência das parasitoses intestinais no município de Ibiassucê-Bahia. Revista Educação, Meio Ambiente e Saúde, Bahia, v.5, n.1, p. 64-71, 2012.

MUNIZ, J. M. Avaliação microbiológica, física e química da água de escolas públicas municipais de Uberaba - MG. 2013. 140f. Dissertação (Mestrado Profissional em Ciência e Tecnologia de Alimentos)- Instituto Federal de Educação, Ciência e Tecnologia do Triângulo Mineiro do Campus Uberaba, Uberaba/MG, 2013.

PARRON, L.M; MUNIZ, D.H.F; PEREIRA, C.M. Manual de procedimento deamostragem e análise físico química de água. Embrapa Florestas, $1^{\circ}$ Edição, p. 1-69, 2011.

PEZENTE, A.W. Análise microbiológica, física e química da água dos bebedouros e torneiras consumida na E.E.B Timbé do Sul, localizada no centro do munícipio deTimbé do Sul-SC. 2009. 43f. Trabalho de Conclusão de curso (Graduação em Farmácia)- Universidade do Extremo Sul Catarinense-UNESC, Criciúma, 2009.

ROQUE, F. C. et al. Parasitos intestinais: Prevalência em escolas da periferia de Porto Alegre- RS. NewsLab, Rio Grande do Sul, p. 152-162, 2005.

SANTOS, J. G. et al. Análise parasitológica em efluentes de estações de tratamento de águas residuárias. Revista de Patologia Tropical, São Paulo, v. 41, n. 3, p. 319-336, jul-set. 2012.

ZULPO, D. L.; PERETTI, J.; ONO, L. M.; GARCIA, J. L. Avaliação microbiológica da água consumida nos bebedouros da Universidade Estadual do Centro-Oeste, Guarapuava, Paraná, Brasil. Revista Ciências Agrárias. v.27, n.2006, p.107-110. 